\title{
Cultural competence in pediatric radiology: Hispanic culture
}

\author{
Nicholas Heitkamp ${ }^{1} \cdot$ Richard B. Gunderman ${ }^{1}$
}

Received: 20 July 2020 / Revised: 20 July 2020 / Accepted: 1 September 2020 / Published online: 19 September 2020

(C) Springer-Verlag GmbH Germany, part of Springer Nature 2020

A Spanish-speaking woman was receiving prenatal care for the delivery of her fifth child. Through an interpreter, her obstetrician asked whether she would like to undergo a tubal ligation after the birth, so that she would not need to worry about contraception in the future. She replied that she would, and informed consent for the procedure was documented. Several months later, the baby delivered and the sterilization performed uneventfully, the patient returned for a routine postnatal care. As the visit was drawing to a close, she turned to the obstetrician and asked, "So doctor, how soon will I be able to become pregnant again?"

In the immortal words of the screenplay of 1967's Cool Hand Luke, what we have here and in countless similar situations in contemporary health care is "a failure to communicate" [1]. In one sense, the woman received first-rate care both her delivery and tubal ligation were technically exemplary. But the patient and physician were separated by a gap in understanding - each heard the other's words but did not really understand what the other intended. Good medical care hinges on mutual understanding between patient and physician, and when the two come from different cultures, extra effort is often needed to ensure such understanding is achieved.

It is vital that all physicians, including pediatric radiologists, understand at the least the fundamental features of other cultures commonly represented in their patient populations. At this point in American history, nowhere is that cultural understanding more urgently needed than in the care of Hispanic patients. Hispanics and Latinos now make up the secondlargest ethnic group in the United States, numbering 60.6 million people [2]. By 2050, their number is expected to increase

Richard B. Gunderman

rbgunder@iu.edu

1 Department of Radiology,

Indiana University,

702 North Barnhill Drive, Room 1053,

Indianapolis, IN 46202, USA to 106 million [3]. On average, they are much younger, less formally educated, and far more likely to be immigrants than the average American [4].

Both the Association of American Medical Colleges (AAMC) and the Accreditation Council for Graduate Medical Education (ACGME) mandate education in cultural competence. The AAMC states that "The faculty and students must demonstrate an understanding of the manner in which people of diverse cultures and belief systems perceive health and illness and respond to various symptoms, diseases, and treatments" [5]. The ACGME specifies that residents should be able "to communicate effectively with patients, families, and the public across a broad range of cultural backgrounds" [6]. Despite such mandates, however, there is work to be done.

To begin with, it is important to recognize that culturally competent care is not guaranteed simply by securing the services of an interpreter. Language barriers are an important aspect, but non-linguistic aspects of culture can be equally or even more influential. For example, different cultures might look at health and disease in ways different from those taken for granted by physicians who have spent their whole lives in the United States [7]. To achieve an appropriate degree of mutual understanding and rapport in the care of Hispanic children and their families, pediatric radiologists need to attempt to see health care from a Hispanic cultural perspective.

Of course, it would be naïve to suppose that Hispanic culture is a monolith, or that any account of it would apply across the board to every Hispanic patient and family. For example, more than 2 dozen nations of origin are represented in the U.S. Hispanic population. Yet even where broad generalizations do not apply in specific cases, they can still serve as a helpful introduction to the sorts of considerations a culturally competent pediatric radiologist needs to be attuned to. Deepening awareness of such distinctive cultural features is not only necessary to care well for such patients but also interesting in its own right. Consider some examples.

One distinctive feature of Hispanic culture concerns the answer to the question, "How are you?" Asked that question by a physician, most Americans would reflect on how they 
personally have been feeling and then answer. By contrast, Hispanic patients might find it difficult to answer such a question before reflecting on their family and community [8]. The understanding of health and disease is likely to be more social or interpersonal than many Americans would take for granted. So it might be helpful to ask first about the patient's family before inquiring about a Hispanic patient's health, and pediatric radiologists should not be surprised when some patients first refer to their family's status before their own.

Another distinctive feature of many Hispanic patients is the desire to avoid creating any breach in the patient-physician relationship [9]. Compounded by the fact that Hispanic patients tend to have less formal education, this reluctance to risk causing offense can make Hispanic patients less likely to express dissatisfaction, to ask questions, and to request clarification of responses $[8,10]$. The patient might be thinking, "If I ask the doctor a question, perhaps she will think I don't trust her, or perhaps it will reveal my lack of education." This makes it especially important that pediatric radiologists make clear their openness to questions and concerns.

Hispanic patients are also likely to approach their health care in more of a family-inclusive manner. Instead of just a parent, multiple family members might accompany a child. Patients and family members who are reluctant to make a health care decision on their own might be revealing not indecisiveness but a cultural conviction that the whole family needs to participate in such decisions [8]. In addition, many Hispanic families might regard women as the natural gobetweens in the patient-physician relationship, because men are often seen as providers and women as caregivers [7]. In general, traditional gender roles are more likely to be reflected in Hispanic culture [7].

Pediatric radiologists should also be careful not to assume that Hispanic patients and families have the same general level of understanding of medical terms and the same access to care as others. In many cases, primarily related to socioeconomic circumstances, everyday aspects of life such as transportation can represent a greater hurdle [11]. Moreover, Hispanic families are often more reliant on traditional systems of diagnosis and therapy, for example, the notion that some conditions are "hot" and others "cold" [12]. Good medical care should not resemble a war between cultures, and the key is to rely on cultural understanding and compassion to ensure that patients are well cared for.

On average, health care outcomes are not as favorable for Hispanic patients. At least by conventional medical standards, Hispanic children are more likely to be misdiagnosed by their parents [13]. When they are admitted to the hospital, they are more likely to suffer serious complications [14]. When they are discharged from the hospital, they are more likely to return to the emergency department [10]. And across the board, Hispanic pediatric patients are approximately twice as likely to experience serious medical events [7]. The reasons for these health disparities are complex, but one contributing factor is likely to be cultural barriers.

More broadly speaking, key Hispanic concepts that shape health care experiences include simpatia (kindness), personalismo (friendliness) and respeto (respect) [12]. Kindness involves reaching out and caring for others as human beings, which means that patients sometimes show sincere interest in how the physician is doing. Friendliness can mean, among other things, inquiring about the physician's family, as well as the physician him- or herself, with the expectation that the physician would do the same. And respect means being mindful of the importance of family and culture, such as welcoming family members to the care environment and showing respect for elders.

As these examples illustrate, an understanding of culture in this case, Hispanic culture - can go a long way toward enhancing communication and the overall quality of the patient-physician relationship. It is important, however, for pediatric radiologists to avoid a patronizing attitude. In some respects, Hispanic culture might seem inferior, but in fact it is rich and vibrant and plays an important role in helping Hispanic patients and families thrive, both inside and outside the health care system. Physicians such as pediatric radiologists often have a lot to learn from Hispanic culture, and those who regard the flow of knowledge and understanding as a two-way process stand the best chance of providing the best care.

\section{Compliance with ethical standards}

Conflicts of interest None

\section{References}

1. Rosenberg S (1967) Cool hand Luke [motion picture]. Jalem Productions, Beverly Hills

2. Noe-Bustamante L, Lopez M, Krogstad J (2020) U.S. Hispanic population surpasses 60 million in 2019, but growth has slowed. Pew Research Center website. https://www.pewresearch.org/facttank/2020/07/07/u-s-hispanic-population-surpassed-60-million-in2019-but-growth-has-slowed/. Accessed 19 July 2020

3. Krogstad J (2014) With fewer new arrivals, census lowers Hispanic population projections. Pew Research Center website. https://www. pewresearch.org/fact-tank/2014/12/16/with-fewer-new-arrivalscensus-lowers-hispanic-population-projections-2/. Accessed 19 July 2020

4. Vega WA, Rodriguez MA, Gruskin E (2009) Health disparities in the Latino population. Epidemiol Rev 31:99-112

5. Association of American Medical Colleges (2005) Cultural competence education. AAMC, Washington, DC. https://www.aamc.org/ system/files/c/2/54338-culturalcomped.pdf. Accessed 26 Aug 2020

6. Accreditation Council for Graduate Medical Education (2017) Common program requirements. ACGME, Chicago. https://www. acgme.org/Portals/0/PFAssets/ProgramRequirements/CPRs_201707-01.pdf. Accessed 26 Aug 2020 
7. Kim-Godwin Y, McMurry MJ (2012) Perspectives of nurse practitioners on health care needs among Latino children and families in the rural southeastern United States: a pilot study. J Pediatr Health Care 26:409-417

8. Seltz LB, Zimmer L, Ochoa-Nunez L et al (2011) Latino families' experiences with family-centered rounds at an academic children's hospital. Acad Pediatr 11:432-438

9. Alegria M, Sribney W, Perez D et al (2009) The role of patient activation on patient-provider communication and quality of care for U.S. and foreign born Latino patients. J Gen Intern Med 24: 534-541

10. Miquel-Verges F, Donohue PK, Boss RD (2011) Discharge of infants from NICU to Latino families with limited English proficiency. J Immigr Minor Health 13:309-314
11. Enlow E, Herbert SL, Jovel IJ et al (2014) Neonatal intensive care unit to home: the transition from parent and pediatrician perspectives, a prospective cohort study. J Perinatol 34:761-766

12. Juckett G (2013) Caring for Latino patients. Am Fam Physician 87: 48-54

13. Palau MA, Meier MR, Brinton JT et al (2019) The impact of parental primary language on communication in the neonatal intensive care unit. J Perinatol 39:307-313

14. Cohen AL, Rivara F, Marcuse EK et al (2005) Are language barriers associated with serious medical events in hospitalized pediatric patients? Pediatrics 116:575-579

Publisher's note Springer Nature remains neutral with regard to jurisdictional claims in published maps and institutional affiliations. 